\title{
Partner Interference with Health Care: Do We Want One More Piece of a Complex Puzzle?
}

\author{
Christina Nicolaidis, $\mathrm{MD}, \mathrm{MPH}^{1,2}$ \\ 'Division of General Internal Medicine and Geriatrics, Department of Medicine, Oregon Health and Science University, Portland, OR, USA; \\ ${ }^{2}$ Department of Public Health and Preventive Medicine, Oregon Health and Science University, Portland, OR, USA.
}

DOI: $10.1007 / \mathrm{s} 11606-007-0262-9$

(c) 2007 Society of General Internal Medicine 2007;22:1216-1217

A $\mathrm{S}$ I sit down to write, scattered images of former patients fill my mind: a well-educated, elderly woman presenting to the hospital 2 days after having a large myocardial infarction; a young diabetic woman with erratic blood glucose control; one of my colleague's "frequent flyers" coming in to see me on a Friday afternoon, panicked, asking for yet another early refill of her hydrocodone; a very ill, middle-aged woman whose doting husband kept immaculate notes on her many medical issues and 12 medications. Each of these women has her own, complex story. Each had a partner who negatively interfered with her medical care.

McCloskey et al., in this issue of the Journal of General Internal Medicine, ${ }^{1}$ found that 1 in 20 female outpatients reported that their partners had prevented them from seeking care or interfered with their health care. A recent history of intimate partner violence (IPV) raised the odds of having a partner interfere with care by 7.5. The presence of a man accompanying the patient to the visit raised the odds twofold, independent of IPV history. Partner interference was, in turn, associated with having poor health (odds ratio 1.8).

None of these findings would surprise a domestic violence advocate. The grassroots domestic violence movement has for decades conceptualized battering as a pattern of coercive behaviors where physical violence is only one of many strategies used to gain power and control over an intimate partner. Any advocate working directly with IPV survivors can give examples of how batterers interfered with clients' health care-sometimes to deter discovery of the abuse; often as another (potentially very effective) way to exert control.

Yet what may be a truism to a domestic violence advocate often is not believed or utilized in health care. Sometimes, there is a legitimate concern about the lack of empiric data supporting advocates' beliefs. Sometimes, there is appropriate hesitation about overly generalizing to broader populations information gained from the small subset of women who seek domestic violence services. Up to now, no one, to my knowledge, had ever formally assessed partner interference with health care, so all one could rely on was anectodal stories at

Published online June 28, 2007 best. The study by McClusky et al. of over 2,000 women from diverse backgrounds, seeking outpatient care in 7 metropolitan-area hospitals, now provides us with important data regarding the high prevalence of partner interference amongst women seeking outpatient care, its strong association with IPV, and its potential relationship with health outcomes. Of course, as the authors thoughtfully discuss, the study has several limitations, but whether or not an individual provider uses these findings is likely not related to the study's limitations.

The real question is how do we value information about the complexity of our patients' lives? In a setting of worsening time pressures and financial constraints, it is often tempting to hide behind the cloak of "evidence-based medicine". In 2004, the U.S. Preventive Services Task Force (USPSTF) found that there was insufficient evidence to recommend for or against screening for IPV in primary care settings. ${ }^{2}$ Though the task force did not intend their recommendations to curtail inquiry about IPV, ${ }^{3}$ I regularly hear providers justify their lack of attention to possible IPV - even in settings where there is increased clinical suspicion - with references to the Task Force's recommendations or arguments about the lack of evidence that identification or referral improves outcomes.

This study does not fill any such gaps in the evidence. Who knows if obtaining information about partner interference with health care would have any measurable effect on patient outcomes? It is not even clear that finding out about partner interference with health care should always change management. However, I do know that it sheds important light in helping to understand individual patients, their behavior, and their relationships with providers.

The study by McCloskey et al. has many clinical implications. First, as was the case with my elderly patient who presented 2 days after her myocardial infarction, a delay in care may be an important clinical sign to the presence of IPV. Despite the controversy about routine screening for IPV, the USPSTF does recommend case finding efforts in situations of increased clinical suspicion. ${ }^{2,3}$ In this case, the delay in care was the only clue I had to possible IPV. After direct inquiry about IPV, the patient disclosed ongoing abuse by her husband. The physical abuse had subsided over time, but the controlling behaviors had only intensified. Forbidding her to come to the hospital until he decided she could do so was one of many tactics her husband used to exert his control over her. She had never previously discussed the abuse with anyone. Learning about the abuse allowed us to give her appropriate counseling and offer her referrals to domestic violence services. 
Next, as was the case with my poorly controlled diabetic patient, partner interference with health care may potentially explain poor health outcomes. Such information may lead to important changes in strategies for improving chronic illness. Although I had known about her involvement with an abusive partner and had offered her referrals to domestic violence services, the patient was not ready to end her relationship. My biggest concern was stabilizing her diabetes. Only after many visits where I had made great effort to show respect for her decision to stay with her partner and to gain her trust did I learn that her partner would routinely punish her by taking away her insulin. Knowing this information, I could work with her on strategies to ensure reliable access to insulin, as opposed to trying to adjust her dose or teach basic diabetes information that she already knew.

Third, information about partner interference can offer a deeper understanding of the complex factors that influence patient behavior. On one of her many urgent care visits with me, I learned that the young woman with the repeated early refill requests for opiates was involved with an abusive boyfriend who would force her to do many things, include obtaining medications for him. Learning this piece of information did not necessarily provide an easy plan of action, but it did allow us to go beyond a simplistic approach to her drug seeking, which may have otherwise resulted in her being discharged from the practice. Though my colleague does not report a clear way that this information has changed his management, and though 6 years after this disclosure, she is still with her abusive partner, it is interesting to note that she has been able to maintain a close therapeutic relationship with my colleague this whole time and has made many important improvements in her health.

Lastly, McCloskey et al. found that women who were accompanied to a visit by a man reported greater levels of partner interference with health care, independent of whether or not the woman disclosed a history of abuse. At first, I was very impressed with the doting nature of my patient's husband and the meticulous way he managed her complicated medical regimen. As is my usual practice, I interviewed her alone and asked about IPV, but she adamantly denied it. Over time, though, I would notice little clues that the relationship was more problematic than it appeared: demeaning comments about his wife in my presence; furtive glances to put her in her place; little room for her to answer my questions herself. I routinely asked him at each visit to leave the room while I examined her and slowly, over time, I started to hear more about the depths of his alcoholism and emotional abuse. After her third intensive care unit stay, she admitted that his controlling behavior had escalated and that he was now regularly interfering with her ability to take her medications as directed. Ultimately, she moved in with her daughter who took over being her caregiver and helped keep her out of the hospital. Of course, the majority of men who accompany their partners to clinic are not abusive or interfering with their health care. But McCloskey's findings remind us to be alert to the possibility.

I can think of another dozen or two examples of where I learned that my patients' partners were interfering with their care. In some cases there were clear implications related to this knowledge. Sometimes there were none. I can guess that my counseling or referrals helped some of these patients at some level. For most, I will never know. However, should I be proud of identifying 15 or 30 cases of partner interference over 14 years of clinical practice? McCloskey et al. found that 1 in 20 female outpatients reported partner interference. In a year, how many female patients do I see? Having devoted most of my career to IPV research and education, I am very diligent (and, I hope, skilled) at assessing patients for IPV. My experience and these findings are off by at least an order of magnitude. Why? Further research is needed to understand what women mean when they report partner interference; how important an issue partner interference is for male patients; how partner interference relates to health; what providers can do to elicit accurate information about partner interference; how such information can affect the therapeutic relationship and health outcomes; and ultimately, how to help patients live lives that are free from violence, abuse, and coercion. In the meantime, I will keep trying to respect and understand the complex nature of my patients' lives, one person at a time.

Corresponding Author: Christina Nicolaidis, MD, MPH; Division of General Internal Medicine and Geriatrics, Department of Medicine, Oregon Health and Science University, L475, 3181 SW Sam Jackson Park Road, Portland, OR 97239, USA (e-mail: nicolaid@ohsu.edu).

\section{REFERENCES}

1. McCloskey LA, Williams CM, Lichter E, Gerber M, Ganz ML, Sege R. Abused women disclose partner interference with health care: an unrecognized form of battering. J Gen Intern Med. 2007;22

2. U.S. Preventive Services Task Force. Screening for family and intimate partner violence: recommendation statement. Ann Intern Med. 2004; 140:382-6.

3. Calonge N, Allan JD. Screening for family and intimate partner violence [response]. Ann Intern Med. 2004;141:82. 